Article

\title{
Promoting Social Competence in Preschool with an Executive Functions Program Conducted by Teachers
}

\author{
Miriam Romero-López, M. Carmen Pichardo *, Judit Bembibre-Serrano and \\ Trinidad García-Berbén \\ Department of Evolutive and Educational Psychology, University of Granada, 18071 Granada, Spain; \\ miriam@ugr.es (M.R.-L.); jbembibre@ugr.es (J.B.-S.); tgarciab@ugr.es (T.G.-B.) \\ * Correspondence: pichardo@ugr.es; Tel.: +34-958-249-658
}

Received: 22 April 2020; Accepted: 25 May 2020; Published: 28 May 2020

check for updates

\begin{abstract}
The objective of this research is to examine the effectiveness of the "Executive Function Training Program in Preschool" (EFE-P) that includes real-world activities and applies different required methodologies for a sustainable education. In addition, it is evaluated whether the improvement of executive functions is transferred to the social competence domain. The study involved 100 students aged 5-6 years, of which 50 were randomly assigned to the active control group and 50 to the experimental group. Executive functions (BRIEF-P) and social competence (BASC and PKBS-2) were measured at two time points (pre-intervention and post-intervention). Data were analyzed using the Generalized Estimating Equation (GEE) for repeated data and results showed that children in the experimental group obtained better scores on executive functions and social competence compared to their peers in the control group. It is discussed if the executive functions training can be effective in improving social competence as long as the programs include real-world activities that encourage such transfer, as the EFE-P does.
\end{abstract}

Keywords: executive function; inhibitory control; working memory; cognitive flexibility; social competence; social skills; transfer; sustainability education; teacher training

\section{Introduction}

The social condition of human beings is indisputable to the extent that it is almost impossible for us thriving without a communal network. Therefore, it is stated that we are born with a preprogramed blueprint to establish interpersonal bonds in our most immediate contexts [1,2]. In a normotypical milieu, parents are usually the first social environments, and in the early stages, the attachment to relatives is decisive for social adaptation throughout life. Later, at least in the developed countries, children will move on to the preschool context, a key stage for cognitive, emotional and interpersonal development [3]. At this moment, children enter school for the first time and must learn to establish relationships with peers [4]. Furthermore, infants begin to establish other forms of attachment related to objects, places, symbols or concepts [5]. In this way, they elaborate emotional security bonds to school, just as they did in the family context. Along the preschool stage, pupils will develop a place identity integrated by a set of cognitions about the physical world around them, including the academic context. These cognitions represent memories, attitudes, values, meanings, and conceptions of behavior, feelings and experiences related to the variety and complexity of the ecological conditions in which the person lives [6]. In this sense, Ramkissoon and colleagues found that attachment to a place was a second-order factor, composed of sub-dimensions of place dependence, identity, affect and social bonding. This kind of attachment within to the school center will be closely related to the interpersonal relationships and 
social bonding that the pupil establishes along this period $[7,8]$. There is a need to pay special attention to the guidance of the teacher figure along this process.

In fact, the preschool classroom becomes a new social environment where children will be able to develop and improve their emotional and interpersonal skills, learn and understand established social norms, and make their first friends. Peer interactions provide opportunities to practice cognitive, emotional, and social abilities and acquire new aptitudes through observation of other competent children and teachers. Success in creating new friendships will be determined by social competence [2]. In addition, today these links between people have been increased and enlarged due to the impact technology and social networks $[9,10]$.

In the same line, successful functioning throughout life, at school or at work, in social interactions and in physical and mental health, demands effective developed executive functions. When the effectiveness of training programs in executive functions is analyzed it has shown that these higher mental processes can be improved in the preschool stage. However, there is a wide debate on whether executive improvement is transferred to other untrained domains such as social competence. It is reported that the type of intervention could influence executive transfer but data remain inconsistent. In contrast with the negative results with computerized training, recent research found that only the programs that implement daily life situations or real-resembled problems in the classroom setting allow the generalization of improvements in executive functions to another interpersonal or academics skills and processes [11]. In addition, it is highlighted the need to design this kind of program in order to instruct the teachers as they could become the best competence models since they represent the main bond between students and the factual school context.

For this reason, this study aims to analyze whether the improvement of executive functions after the implementation of a program based on real-situation activities by the teachers in the preschool classroom can transfer to other areas where executive functions have a key role, such as social competence. A validated program could be a useful tool for teachers in order to provide them with different efficient strategies to promote the executive and social development of their students.

\section{Theoretical Background}

Social competence is defined as effectiveness in the interpersonal contexts [12]. The terms social competence and social skills are often used in an interchangeable way. However, social skills are considered specific learned behaviors that make it easier to interact efficiently with the others. Therefore, social competence refers to the use of social skills in appropriate relational environments, while social skills are the various specific behaviors that constitute social competence [13,14].

At the same time, social competence and skills are among the most significant achievements in childhood for interpersonal adaptation along adolescence and the adult stage. These abilities, such as cooperation, empathy, or autonomy promote the well-being and the adjusted status in the diverse contexts of human interaction: home, school or work, friendship, and romantic links $[15,16]$. So, in the first years, social skills facilitate the establishment of positive exchanges among peers and allow them to learn positive behaviors through the significant others modeling [14,17]. Similarly, high social competence promotes school readiness and academic achievement [18]. In contrast, children with deficits in the social domain may display maladjusted bonds with their parents and siblings, peers, or teachers, exhibiting deviated emotional and behavioral problems, specially externalizing ones [14,18].

Due to the formerly referred negative consequences that are linked to the developmental deficits in the interpersonal domain, a certain amount of research has tried to find the main predictors of social competence, with executive functions being one of the most studied in recent years [19]. The term of executive functions includes a set of skills that enables people to formulate and reach goals through planning and monitoring their progress, while avoid behaviors, thoughts or feelings that interfere with their achievement. Thus, these higher mental functions allow the control of cognitive and socio-emotional processes [20]. Three executive components are commonly distinguished, namely, inhibitory control, working memory, and cognitive flexibility [20-22]. 
Inhibitory control permits one to be able to perform tasks while maintaining attention and avoiding irrelevant stimulus that distract individuals from their goal [20,21]. In addition, it prevents highly learned, automatized, or impulsive responses instead of other more appropriate and effortful voluntary behaviors [23].

Inhibitory control is one of the most important executive components for the development of social competence in preschool and elementary school $[24,25]$. To enact interpersonal adaptive behaviors demands the regulation of dominant aggressive responses [17]. For example, when a child takes away another child's toy, this one must constrain his impulse to react with violence and choose a more socially appropriate conduct as a verbal request or to offer a cooperative game. In addition, inhibitory control promotes respect for established social norms and contextual adjustment and is fundamental to establishing positive relationships [26,27]. Definitely, this process is critical because it allows people to be able to think before speaking or acting, to give a thoughtful rather than an impulsive response, to remain on task despite distractions, or to resist the temptation to do something that could be inappropriate or useless in the short term [28].

On the other hand, working memory represents the ability to manipulate mental representations, that is, to update data for responding to the demands of a task or a context while making it possible to establish connections between new information and previous knowledge [29]. It has a limited capacity that increases with age reaching the mature levels around the first years of primary school. This executive component is also essential for social competence as makes it easier to remember the socially appropriated behaviors for different contexts and the causal relationships between external or internal environments (thoughts, emotions, etc.) and effective responses inside the group. Children with poor working memory have troubles retrieving, actualizing, and distinguishing between rewarding or penalized conducts for reaching their social goals [30].

Finally, cognitive flexibility is another executive component closely related to social competence. It promotes the creation and use of assorted strategies for problem solving. In this way, it enables an individual to analyze a given situation from diverse perspectives, develop new solutions and think creatively. Furthermore, it involves not only the use of divergent strategies for the resolution of cognitive or emotional conflicts but also allows for the understanding of the solutions that other people employ $[20,23]$.

In this way, cognitive flexibility makes it easier for children to resolve their conflicts in a creative way and to propose solutions that benefit themselves but, at the same time, also take others into account. Then, it could contribute to the cooperative and prosocial behavior. For example, when two kids fight because they want the same toy, a cognitively flexible child might propose playing together [31].

The first signs of the executive functions emerge in preschool and continue to develop during adolescence through to adulthood [32]. This long period of development is protracted to the maturation of the prefrontal cortex, where the main neural correlates are located [33]. However, the preschool age is critical: at this stage it is observed that the largest growth in executive processes takes place [34]. The high speed in prefrontal structures maturing from age three to five years promotes flexible thinking and behavior, initial steps for self-regulation and adaptation to norms, and decreases the reactive response to contextual cues. After that, executive functions rapidly progress along the elementary education years [35]. Moreover, the brain has greater neuronal and behavioral plasticity during preschool [36]. Accordingly, this period of life shows its relevance for building strategies to improve executive functions $[37,38]$.

The majority of children will develop their cognitive and social skills through interaction with teachers, parents, siblings, and peers in a relatively automatic process [39]. However, the increasing amount children entering school with problematic and challenging behaviors has encouraged the design of programs for the improvement of social competence. Some of the most widely applied interventions to enhance these abilities are The Incredible Years [40] and Promoting Alternative Thinking Skills (PATHS) [41]. Recent studies have shown the specific effectiveness of those programs to promote social 
competence [42,43]. However, the named programs only focus on socio-emotional processes and do not take into account other decisive aspects of social competence such as executive functions.

With regards to executive functions and among the interventions included into the regular curriculum of first school levels, two programs stand out. On the one hand, Tools of the Mind: The Vygotskian Approach to Early Childhood Education [44] is aimed at improving both executive functions and prosocial behavior. The second program is the Chicago School Readiness Project (CSRP) [45], built to promote executive functions especially among children growing up in high rates of poverty and crime contexts. Both of them have demonstrated their effectiveness in improving executive performance [46,47].

There are also short-term programs with a more intensive schedule: the implementation usually takes between one week and one month. Examples of this type of intervention are the Cogmed Working Memory Training, the program developed by Röthlisberger, Neuenschwander, Cimeli, Michel, and Roebers [48] and the one designed by Traverso, Viterbori, and Usai [49]. In general, short-term programs appear as also effective in improving working memory $[48,50,51]$ and cognitive flexibility $[48,52]$. However, the data about the enhancement of inhibitory control are inconsistent. While Röthlisberger et al. found a significant improvement in inhibitory control after the implementation of their program, another three studies did not observe the same advantage $[51,53,54]$.

In addition, to compare executive function training programs is complex because they are designed to focus on one or various executive components and with a different number of sessions, implementation schedules, materials, or group sizes for shared activities (small group, large group, or individual modality). However, despite the fact that most interventions in executive functions have been shown to be effective for their enhancement, there is little research around if this improvement is transferred to the social domain. Since several studies have found that children who perform an executive task better exhibit an adjusted social competence $[17,26,27]$ it could be inferred that the improvement of executive functions will be bonded with an increasing social competence. However, evidence points out that individuals present difficulties in generalizing what they have learned in one context to another untrained context.

Currently, literature about mechanisms to potentiate the transference of executive functions to other domains has focused on working memory, while inhibitory control and cognitive flexibility remain less investigated despite their relevance for adaptive and creative behavior [55]. Research on working memory transfer reveals how much hard is the generalization of learned or trained abilities in a particular task to a different task or context [56-58]. Several meta-analytic studies have shown that although improvement in working memory is possible $[59,60]$ this enhancement is not transferred to other skills such as social and emotional competence or academic performance [55].

The research about transference among domains must be performed because the long-term goal of executive training ought to take into account the improvement of children's daily functioning [61]. For this reason, if instruction in executive functions components aims to be effective in enhancing social competence, it is needed to include activities that strengthen the generalization, focusing not only on the cognitive processes of executive functions but also on those one that facilitate children's positive relationships.

On the other hand, the design of programs that teachers of preschool education level can apply by their own, as another tool into their methodological resources, would have positive effects on improving the cognitive and social functioning of their students and, therefore, on the relational climate of the classroom. This benefit will be especially relevant in preschool settings, as research shows that younger children profit more from intervention programs than older children [62].

In addition, to provide realistic and context-focused learning settings through a wide range of student-centered methodologies, such as problem-based approach, case studies, and experiential strategies, appears essential for promoting reflection, active engagement with the community, self-directed learning, and critical thinking. These methodologies could promote the competence 
to deal with different social demands and are therefore basic to the development of sustainable education [63].

Therefore, and taking into account the theoretical review carried out, the present study displays the following objectives and contributions:

- Firstly, this current paper exposes the effects of implementing the Executive Function Training Program in Preschool Education (EFE-P) designed for the present research and whose main aim is the improvement of the executive functions, not only focusing on cognitive processes but also gathering behavioral and emotional components of these functions. To our knowledge, no executive training program that can be applied within the regular curriculum in the preschool stage and validated for the Spanish population has been devised. Another contribution of the present program is that, besides its construction is based on other ones that have proven their effectiveness such as Tools of the Mind, it offers different required methodologies for the progress of sustainable education, including problem-based learning activities, case studies, simulation games, and cooperative research [63]. Likewise, it has been created to be carried out by teachers after their training. This instruction provides preschool education teachers with tools and strategies to enlighten their students how to operate in a sustainable world.

- Secondly, the effectiveness of the program in improving social competence is analyzed. In this case, the objective is to clarify some of the mechanisms that let explain the transfer of the executive functions that are trained in the infancy stage because the published studies on the topic show inconsistent data. On the one hand, the meta-analysis carried out by Kassai, Futo, Demetrovics, and Takacs [55] seems to indicate that children at the preschool educational level have difficulties in generalizing executive trained skills to other activities of daily life. However, another recent meta-analysis by Scionti, Cavallero, Zogmaister, and Marzocchi [64] actually found transfer effects. However, neither meta-analysis explores what happens with the transfer of executive functions to another domain such as the social one, but only focuses on whether the improvement of a particular component of executive functions is transferred to another component (for example, whether enhanced inhibitory control results in increased working memory).

Since the EFE-P program has been designed to include social activities where executive functions play a key role, children who participate in its implementation are expected to improve their executive functions and social competence when they are compared to their peers in the control group.

\section{Materials and Methods}

\subsection{Participants}

The sample involved 100 pupils in the last year of nursery education, aged between 5 and 6 years (Mean age $=5.48$, Standard Deviation age $=0.23$ ). The experimental group eventually included 50 children, 27 boys and 23 girls, as did the control group, which also extended to 50 children, 27 boys and 23 girls. Inclusion criteria included no history of chronic physical illness and neurodevelopmental disorders or sensorimotor and intellectual disabilities. For this reason, although the initial sample covered 110 students, 10 of them were excluded because they did not meet the prerequisites.

The participants were enrolled in the last year of kindergarten and attended the same school. It was decided to use students from a unique school to control educational methods, school philosophy, physical space, and activities, as well as demographic parental variables, since the children live in the same neighborhood. The ethnicity in all cases was Caucasian/European with a middle familial socio-economic status.

\subsection{Instrument}

Executive functions were evaluated with the Behavior Rating Inventory of Executive Function-Preschool Version (BRIEF-P) $[65,66]$. This questionnaire is a standardized instrument 
that allows the valuation of the executive components in different environments for children, such as the school context. It is answered using a Likert-type frequency scale with three response options: never, sometimes, and frequently. It is composed of 63 items that are framed within five clinical scales. However, only the 43 items of the following scales were used for this research: deficits in the inhibition for detecting control problems in the child-that is, in the capacity to avoid, resist, or not react to an impulse-as well as the difficulties in halting or recognizing behaviors that are appropriated for specific circumstances (16 items, e.g., "Is unaware of how his/her behavior affects or bothers others"); deficits in working memory, measuring the challenges in updating information in order to complete a task or provide a response (17 items, e.g., "When given two things to do, remembers only the first or last"); and deficits in flexibility, evaluating the difficulties in shifting between one situation, activity or aspect of conflict to another, as required by contextual demands (10 items, e.g., "Becomes upset with new situations"). High scores on any of the BRIEF-P scales indicate the presence of problems in the area represented by that scale. Thus, for example, high inhibition deficit punctuation indicates impulse control and unadjusted behavior. Reliability analyses confirmed the internal consistency across the scale in the Spanish sample, obtaining the following scores: deficits in inhibition $=\alpha=0.93$; deficits in working memory $=\alpha=0.90$; and deficits in flexibility $=\alpha=0.78$.

The evaluation of social competence was carried out through two questionnaires. On the one hand, the Preschool and Kindergarten Behavior Scale-2 (PKBS-2) $[15,16]$ that is answered using a Likert-type frequency scale with four response options, ranging from never to frequently. In addition, it is made up of two scales, social competence and behavioral problems. However, for this research only the 34 items of social competence were applied: social cooperation that assesses the child's social adjustment in relationships with adults and peers (12 items, e.g., is cooperative); social interaction measures the acquisition and maintenance of acceptance and friendship with others (11 items, e.g., participate in family or school conversations); and social independence evaluates behaviors and characteristics for autonomy within the peer group setting (11 items, e.g., plays with different children). Reliability analyses confirmed the internal consistency across the scale in the Spanish sample, obtaining the following scores: social cooperation $=\alpha=0.93$; social interaction $=\alpha=0.94$; and social independence $=\alpha=0.94$.

On the other hand, the Behavior Assessment System for Children and Adolescents (BASC) $[67,68]$ is built as a Likert-type frequency scale with four response options ranging from never to almost always and composed of 14 clinical scales and 5 global dimensions. However, for this research only the 18 items corresponding to the following scales were administrated: adaptability, for evaluating the child's ability to easily adapt to changes in the environment (8 items, e.g., "Is stubborn"); and social skills, assessing the skills needed to interact successfully with peers and adults in the home, school and community settings (10 items, e.g., "Admits his mistakes"). The internal consistency indices for this research were 0.68 for adaptability and 0.91 for social skills.

\subsection{The EFE-P Program}

The EFE-P program has been designed to improve the executive functions in children from 5 to 6 years old. It spends 21 sessions for approximately 30 minutes, twice a week. These sessions are mainly play-based in order to motivate the kids and include methodologies that are demanded for the development of sustainable education, such as problem-based learning activities, case studies, simulation games, and cooperative research.

In addition, one of its main advantages is that it takes into account the more behavioral aspects of executive functions requested for proper social interaction. Thus, it includes both cognitive activities and tasks more oriented to the comportment contexts. All program sessions start by introducing children a social dilemma where executive functions play a key role: an illustrated story that presents the main characters of the program, Carla and Pepe, having a conflict. For example, a drawing shows Carla has taken Pepe's ball away and Pepe hits her to get it back. Students then discuss about what the characters should have done to solve the conflict in a more positively and about what they tend to do 
when faced with a similar situation. In addition, they are taught different impulse control techniques, such as the traffic light technique or the turtle technique, and role-playing are made to guide diverse solutions they should have applied. Other sessions include popular stories famous among children where character roles are changed in order to increase cognitive flexibility. For example, the tale of Little Red Riding Hood is related, but in this occasion, the wolf is good and Little Red Riding Hood is the one who behaves inappropriately. In addition, the program includes visual, auditory, and physical activities (i.e., distributing colored rings on the floor and assigning a sticker of one color to each child; if the teacher blows the whistle once, the children must get into a hoop of their assigned color, but if she blows it twice, they must get into a hoop of a different color; after a while, the rule is changed and if the teacher blows the whistle once they have to look for a ring of a different color than the one assigned and if she blows it twice they have to look for a ring of the same color). The program also incorporates plastic activities such as, for example, to make a free drawing for 2 minutes and, after this time, exchange it with a partner and continue their partner's drawing.

\subsection{Procedure}

The first step of the present research was the elaboration of a project where all the requirements of the investigation were gathered. Subsequently, this project was sent to the Bioethics Committee on Human Research of the University of Granada, which approved it after ensuring that it fulfilled with data protection and the requirements of the Code of Ethics in Psychology.

Once the permissions were granted, all the nursery schools in the capital of Granada (Spain) were asked to find out if the school management was interested in the teacher training and implementing a program in executive functions. Among all the centers that confirmed their interest, a random selection was made, and one school was chosen.

After selecting the educational centre where the research would be carried out, a meeting was convened with all the parents of the students in the last year of preschool education. At this meeting, the objectives of the research were explained and all attendees signed the informed consent. Those parents who were unable to be present received a letter explaining all the exposed issues and were asked to return it signed if they were interested in the participation of their children.

For the next step, a hired evaluator was trained to record the different behaviors needed to carry out the investigation. In the observation phase (pre and post), the evaluator was provided with a record form for the classroom and another one for the playground to focus on analyzing the frequency of specific behaviors that he would evaluate through the standardized questionnaires later. Likewise, during these two months, an external infant education teacher was instructed to apply the EFE-P program in the experimental group and was told what activities she should implement with the active control group. A double-blind procedure (evaluation and intervention) was used, as both the teacher applying the interventions and the evaluator were unaware of the research objectives.

After the training, the evaluator observed for 4 hours a day and along two months the behaviors of the students of both the active control group and the experimental group, taking into account that the evaluation was made on similar days and at similar times for all the participants. Thus, observations were performed for both groups in similar places and at similar times. After finishing these two months of observation, the evaluator completed the executive function questionnaire (BRIEF-P) and the social competence questionnaires (BASC and PKBS-2) for each participating child (pre-intervention phase).

Once the questionnaires had been fulfilled, the infant education teacher carried out the intervention phase for two and a half months. In this way, she applied the EFE-P program in the experimental group and carried out different activities related to the regular curriculum in the active control group. These activities involved collective games around stories, drawings or brick building toys. As in the evaluation, the days and times of implementation were taken into account, and the schedules and days were rotated so that both children in the control group and those in the experimental group had similar schedules. 
In order to carry out the tasks designed for the control and experimental groups the center provided a classroom that was usually employed for sports activities by the children. The teacher trained in the EFE-P program, on the days and at the times scheduled, conducted the assigned group (control or experimental) to this place. The rest of the students remained in their regular classes with their teachers. As mentioned above, both the period of day when the activities were applied and the time spent with each group were matched.

The post-training evaluation phase began a month later the intervention to avoid the immediate effect of the participants' instruction on the targeted skills. After this latency month, the same pre-intervention phase evaluator started a two-month observation period. Following this observation lapse, the evaluator completed the executive functions questionnaire (BRIEF-P) and the social competence questionnaires (BASC and PKBS-2) for each participating child (post-intervention phase).

The tasks carried out in this research, the activities undertaken and the personnel responsible are shown in Figure 1.

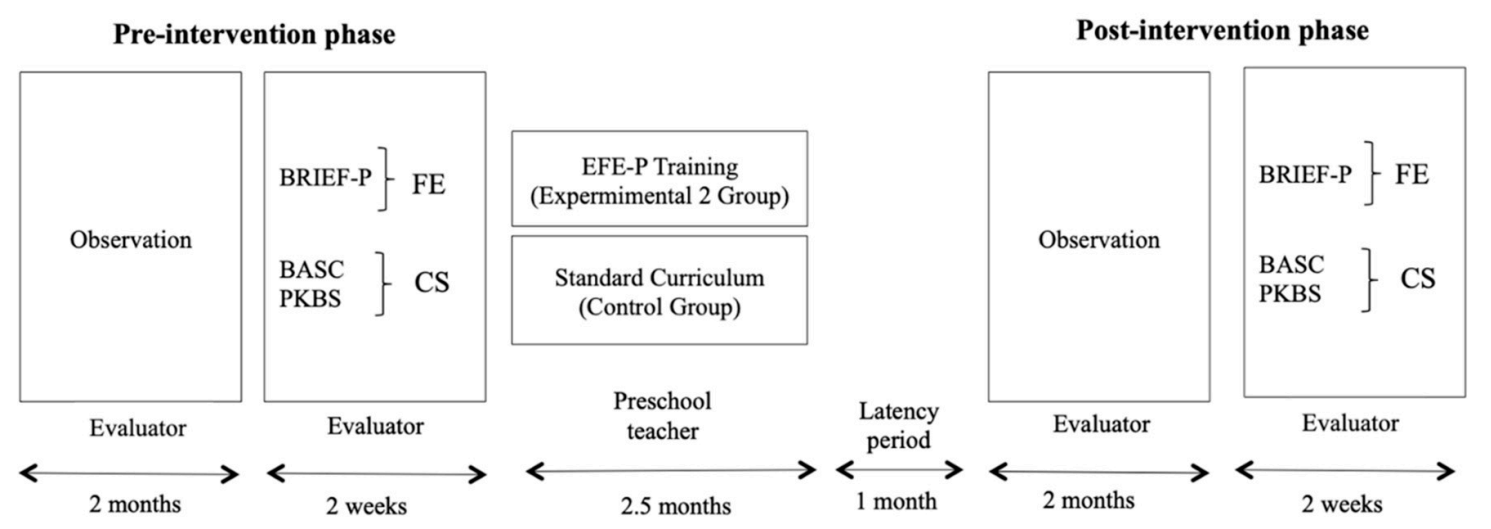

Figure 1. Time distribution of study activities.

Data analysis and the drafting of the research report followed. Finally, the school center was informed of the results obtained.

\subsection{Design and Statistical Analysis}

On the basis of the research objectives and hypotheses described above, this experimental study was designed as an individually randomized trial with two groups (experimental and control) and two phases (times) of assessment (pre-intervention and post-intervention). The random assignment of the children to intervention and control groups was accomplished using computer-generated codes. The groups were coded as $1=$ experimental group and $2=$ control group. The Generalized Estimating Equation (GEE) was used for data analysis. GEE is a repeated-measures regression model that takes into account the correlation of the repeated measures within a person. These models have been considered adequate in longitudinal intervention studies with small populations [69,70]. Chi-squares values were generated from the generalized estimating equation with Gamma loglinear model, for variables related to social competence, and an equation with the Tweedie loglinear model in the variables of executive functions, because they are numerical variables with the possibility of zero in their values. The GEE model incorporated two main effects: a group indicator (experimental and control) and a time variable with two time points (pre-intervention and post-intervention) and their interaction term. This model allowed for group-specific evolutions in developmental performance (from baseline-midline and from baseline-end line). Finally, Cohen's d statistic was also used to estimate the effect size of the intervention for both groups (control and experimental) - it being one of the most used in the field of education [71]. To facilitate the interpretation of the tool's findings, Cohen established large $(\mathrm{d} \geq 0.80)$, medium $(0.50 \leq \mathrm{d} \leq 0.79)$, and small $(0.020 \leq \mathrm{d} \leq 0.49)$ effects [72]. The Statistics 20 for the Mac version of the Statistical Package for the Social Sciences (SPSS) was used for the different analyses carried out. 


\section{Results}

The mean scores and standard deviations of the participants in the experimental and control groups in the two evaluation phases (pre-intervention and post-intervention) are shown in Table 1.

Table 1. Mean values and standard deviations of the control and experimental groups in the two evaluation phases.

\begin{tabular}{ccccc}
\hline \multirow{2}{*}{ Variables } & \multicolumn{2}{c}{ Experimental Group } & \multicolumn{2}{c}{ Control Group } \\
\cline { 2 - 5 } & Pre-Intervention & Post-Intervention & Pre-Intervention & Post-Intervention \\
\cline { 2 - 5 } & Mean (SD ${ }^{\mathbf{1}}$ ) & Mean (SD) & Mean (SD) & Mean (SD) \\
\hline Executive Functions (Deficits) & & & $0.38(0.05)$ \\
\hline Inhibition & $0.40(0.05)$ & $0.07(0.02)$ & $0.44(0.06)$ & $0.21(0.03)$ \\
Flexibility & $0.24(0.04)$ & $0.06(0.01)$ & $0.26(0.04)$ & $0.39(0.04)$ \\
Working Memory & $0.46(0.04)$ & $0.08(0.01)$ & $0.45(0.05)$ & \\
\hline Social Competence & & & & $2.10(0,05)$ \\
\hline Social Cooperation & $1.62(0.07)$ & $2.76(0.04)$ & $2.00(0.05)$ & $1.77(0.07)$ \\
Social Interaction & $1.32(0.07)$ & $2.55(0.05)$ & $1.81(0.07)$ & $2.05(0.07)$ \\
Social Independence & $1.57(0.07)$ & $2.67(0.05)$ & $1.92(0.06)$ & $2.07(0.06)$ \\
Adaptation & $2.18(0.04)$ & $2.81(0.02)$ & $1.36(0.08)$ & $1.57(0.07)$ \\
Social Skills & $1.43(0.07)$ & $2.53(0.05)$ & &
\end{tabular}

The experimental group, in the pre-intervention phase, obtained slightly lower mean scores than the control group in deficits in executive functions (inhibition, flexibility, and working memory). In the post-intervention phase, both experimental and control group reduce their scores, although the mean values of the experimental group, in all the deficits of executive functions evaluated, are very low and significantly smaller than those reached by the control group.

On the other hand, experimental and control groups present similar mean scores in the variables of social competence in the pre-intervention phase. However, the control group obtained higher values in social interaction, social cooperation, and social independence, while the experimental group presented higher data in adaptation and social skills. Both groups increase their outcomes in the post-intervention phase in all the social competence variables analyzed. However, the control group improved slightly while the experimental group obtained a considerable gain. Both experimental and control group in the two phases and in the different variables analyzed present very low standard deviations, reflecting little dispersion of values.

In order to evaluate the effectiveness of the EFE-P program on the variables it trains, the analysis of its effects on flexibility, inhibition, and working memory was performed. For this purpose, through the GEE, the scores obtained by the participants in the two evaluation phases (pre-intervention and post-intervention), differentiated in groups (experimental and control), were compared, obtaining the main effects of the group and intervention time factors, and the group $\times$ time interaction effects (see Table 2).

Table 2. Intervention effects on the executive functions of children, using Generalized Estimating Equations (GEE).

\begin{tabular}{ccccc}
\hline Predictor & $\beta\left(\mathbf{S E}^{\mathbf{1}}\right)$ & $\chi^{\mathbf{2}}$ Wald & $p$-value & ${\text { Cohen's } \mathbf{d}\left[\mathbf{C . I}^{2} \text { ] }\right.}^{\mathbf{2}}$ \\
\hline Inhibition & & & & \\
\hline Group & $-1.64(0.26)$ & 39.18 & $<0.001$ & $-1.07[0.65,1.48]$ \\
Time & $0.14(0.02)$ & 35.83 & $<0.001$ & \\
Group $\times$ Time & $1.54(0.13)$ & 126.62 & $<0.001$ & \\
\hline Flexibility & & & & \\
\hline Group & $-1.23(0.28)$ & 18.96 & $<0.001$ & \\
Time & $0.25(0.06)$ & 19.73 & $<0.001$ & $-0.88[0.47,1.29]$ \\
Group $\times$ Time & $1.14(0.15)$ & 61.18 & $<0.001$ & \\
\hline
\end{tabular}


Table 2. Cont.

\begin{tabular}{ccccc}
\hline Predictor & $\beta\left(\mathbf{S E}^{\mathbf{1}}\right)$ & $\chi^{2}$ Wald & $p$-value & ${\text { Cohen's d }\left[\mathbf{C . I}^{2} \text { ] }\right.}^{\text {Working Memory }}$ \\
\hline Group & $-1.52(0.20)$ & 56.49 & $<0.001$ & \\
Time & $0.16(0.33)$ & 25.39 & $<0.001$ & $-1.35[0.92,1.79]$ \\
Group $\times$ Time & $1.53(0.14)$ & 124.24 & $<0.001$ & \\
\hline \multicolumn{5}{c}{${ }^{2}$ C.I Confidence Interval. }
\end{tabular}

In all the variables regarding to the executive functions evaluated, significant main effects were obtained, both from the group factor and the time factor. The participants in the experimental group have lower scores on executive function deficits than the participants in the control group. In terms of time, regardless of whether the groups (control or experimental) in the post-intervention phase the scores in executive function deficits were lower than in the pre-intervention phase.

Likewise, significant interaction effects between the group and time factors were found in all the variables in which the EFE-P program was included. In this sense, the participants of the experimental group, after their participation in the program (post-intervention time) obtained significantly lower scores than the participants of the control group in the inhibition deficit $\chi^{2}(1, N=100)=126.62, p<0.001$, flexibility deficit $\chi^{2}(1, N=100)=61.18, p<0.001$, and working memory deficit $\chi^{2}(1, N=100)=124.24$, $p<0.001$. The effect sizes on all variables were high, ranging from $d=-0.88$ to $d=-1.35$. The negative value of the effect sizes was due to the fact that the scores on all executive function deficits were lower in the first group included in the GEE model (experimental group).

Once the effectiveness of the program in improving the executive functions of the participants was proven, the effect of the program on the different variables of social competence was analyzed. The objective was to check to what extent participation in EFE-P could lead to an increase in social competence. The results of the GEE showed (see Table 3) main effects on the group and time factors in the six variables of social competence (social cooperation, social interaction, social independence, adaptation and social skills). Regarding the main effects of the group factor, children in the experimental group obtained higher scores in social competence than children in the control group. On the other hand, with regard to the time factor, participants in both groups obtained significantly higher scores in the post-intervention phase.

Table 3. Intervention effects on the social competence of children, using Generalized Estimating Equations (GEE).

\begin{tabular}{|c|c|c|c|c|}
\hline Predictor & $\beta\left(\mathrm{SE}^{1}\right)$ & $x^{2}$ Wald & $p$-value & Cohen's d [C.I $\left.{ }^{2}\right]$ \\
\hline \multicolumn{5}{|l|}{ Social Cooperation } \\
\hline Group & $0.27(0.02)$ & 100.10 & $<0.001$ & $2.09[1.59,2.57]$ \\
\hline Time & $-0.04(0.01)$ & 39.71 & $<0.001$ & \\
\hline Group $\times$ Time & $-0.48(0.03)$ & 195.58 & $<0.001$ & \\
\hline \multicolumn{5}{|l|}{ Social Interaction } \\
\hline Group & $0.36(0.04)$ & 73.62 & $<0.001$ & \\
\hline Time & $-0.09(0.01)$ & 67.49 & $<0.001$ & $1.87[1.38,2.34]$ \\
\hline Group $\times$ Time & $-0.56(0.04)$ & 169.38 & $<0.001$ & \\
\hline \multicolumn{5}{|c|}{ Social Independence } \\
\hline Group & $0.27(0.04)$ & 49.93 & $<0.001$ & \\
\hline Time & $-0.08(0.01)$ & 32.99 & $<0.001$ & \\
\hline Group $\times$ Time & $-0.45(0.03)$ & 160.39 & $<0.001$ & $1.49[1.04,1.94]$ \\
\hline \multicolumn{5}{|l|}{ Adaptation } \\
\hline Group & $-0.31(0.03)$ & 102.08 & $<0.001$ & \\
\hline Time & $-0.07(0.01)$ & 57.18 & $<0.001$ & \\
\hline Group $\times$ Time & $-0.18(0.02)$ & 54.78 & $<0.001$ & $2.27[1.71,2.82]$ \\
\hline \multicolumn{5}{|l|}{ Social Skills } \\
\hline Group & $0.48(0.05)$ & 89.54 & $<0.001$ & \\
\hline Time & $-0.15(0.02)$ & 65.08 & $<0.001$ & \\
\hline Group $\times$ Time & $-0,42(0.04)$ & 106.23 & $<0.001$ & $2.19[1.67,2.70]$ \\
\hline
\end{tabular}


In the case of the interaction between the evaluation time and the group, it can be seen that this was significant for all the competence variables. Children in the experimental group scored significantly higher than the control group in the post-intervention phase in social cooperation $\chi^{2}$ $(1, N=100)=195.58, p<0.001$, social interaction $\chi^{2}(1, N=100)=169.38, p<0.001$, social independence $\chi^{2}(1, N=100)=160.39, p<0.001$, Adaptation $\chi^{2}(1, N=100)=54.78, p<0.001$, and social skills $\chi^{2}$ $(1, N=100)=106.23, p<0.001$. The effect sizes were very high for all the competition variables analyzed (Table 3$)$.

\section{Discussion}

Historically, to perform behaviors to help others has been considered a basic social value. Most research in this field, however, has focused on identifying and studying those factors that predict negative or antisocial behaviors, such as aggression, with little attention to the prosocial or cooperative aptitudes that allow children to develop more adaptive conducts [73].

It was not until the 1970s, when there was a change in researchers' concerns and the study of positive qualities as a means of preventing and repairing disruptive behavior began to take on relevance. Implicit in this trend is the assumption that educational interventions would not only decrease children's altered behaviors, but could also enhance and promote positive behaviors [74].

For this reason, the present research analyzed the effectiveness of a training program in executive functions and its influence on improving the social competence of pupils in the final year of preschool education. To this end, the effectiveness of the EFE-P program was first evaluated. The results of the study confirm the initial hypothesis since the students in the experimental group obtained higher performances in inhibitory control, working memory and cognitive flexibility in the post-intervention phase compared to their peers in the control group. So, they exhibit better self-control skills, were more proficient in updating information, and had a greater ability to generate different solutions to a conflict that non-trained schoolmates. We conclude, therefore, that the children who participated in the EFE-P program reduced their deficits in executive functions to a greater extent than their peers who received only standard curricular activities. Those data confirm the effectiveness of the intervention program.

According with the current research, other studies offer evidences about the effectiveness of executive training programs. For example, Traverso et al. carried out an intervention with 75 five-year-old participants that included twelve 30-minute sessions conducted over a month. They found that the children in the experimental group had improvements in inhibition tasks, working memory and cognitive flexibility when they were compared to their peers of the control group [49]. Similarly, Diamond, Lee, Senften, Lam, and Abbott conducted a study based on the application of Tools of the Mind and affirmed that pupils who were engaged in the program increased their daily executive abilities in contrast with the non-trained group [46]. However, as previously mentioned, the EFE-P program adds two advantages to these programs. Firstly, it was validated for the Spanish population, including activities that can be easily incorporated into the ordinary curriculum for children in preschool educational level; and the second strength may be that it uses methodologies that are requested for the development of sustainable education. It seems very productive to provide education professionals with previously validated programs in the contexts that must be put into practice. This kind of strategy can serve as a methodological tool that benefits not only cognitive but also personal and social development of their students.

Moreover, in the present investigation it was found that the students of the control group also improved their executive functions in the post-intervention phase, although to a lesser extent than the experimental group. These results could be supported by those found in studies like the one conducted by Blair and Raver with 754 preschool students. It was based on the application of the Tools of the Mind program and included an evaluation at two time points (pre and post intervention) to test its effectiveness. They stated that both control and experimental groups had experienced benefits in executive functions; however, the experimental group showed greater increase [75]. The authors explained the progress of the control group in two ways: on the one hand, attending school and 
the activities that are included in the regular curriculum at the preschool stage could favor the development of executive functions; secondly, the progress of executive functions accelerates during childhood, especially along the preschool years [20]. Then even without specific training, children meliorate their executive functions, although at a lower degree than those students who participate in instruction programs.

In addition, the initial second hypothesis was confirmed, since the improvements in executive functions were also transferred to the social domain. The children who participated in the EFE-P program not only obtained improvements in the executive components, but also in the different evaluated components of social competence (social cooperation, social independence, social interaction, adaptability, and social skills). The experimental group members were able to reach better adaptation to changes in the environment, to cooperate, to acquire and maintain friendships, and to establish satisfactory interactions in diverse contexts than their peers into the control group.

Similar data were found by Dias and Seabra after applying a program to ameliorate executive functions in the first grade of primary school when they not only observed improvements in these functions, but also these progresses were transferred to the social field [76]. Likewise, Diamond et al. informed that increases in executive functions following the implementation of the Tools of the Mind program were transferred to the social domain too. Specifically, they reported that children who participated in the intervention were able to provide help to their peers when they needed it, encouraged each other, and made sure that all classroom mates had someone to play with [46].

All the referred studies have in common that the programs for the improvement of the executive functions include activities where these higher mental functions facilitate to successfully cope with daily life demands in childhood contexts. However, research that has focused on more cognitive training of executive functions has failed in obtaining the transference effects. In this line, the meta-analysis carried out by Melby-Levàrg, Redick, and Hulme about working memory training (with the control group and pre-post intervention designs) reported that, although after intervention the children in the experimental group obtained higher scores in memory than their peers in the control group, these improvements were not transferred to other processes such as verbal and non-verbal abilities, reading or arithmetic. They concluded that this kind of working memory training programs appeared to produce specific short-term benefits that do not generalize to real-world skills [59]. Similarly, Kassai et al. conducted a meta-analysis for answering whether executive function training had near or far transfer effects. They defined near transfer as the improvement of the executive component being trained, while far transfer was conceptualized as the advantages of the program on other skills not directly instructed. The authors informed that despite that the children improved the trained skills, these improvements had no distant transfer [55].

Therefore, it is possible to infer that individuals improve those skills they practice, but those progressed are not transferred to other skills. For this reason, the design of real-world-focused activities, such as game-based executive training programs included in the regular curriculum, have shown higher benefits than restricted cognitive or computer-based training [28].

For this reason, if executive function training is to be effective in improving social competence, programs need to include activities where these functions are necessary for satisfactory social relations. These results question the practical and theoretical importance of current cognitive or computerized programs as methods of training executive functions.

However, the present investigation has a number of limitations that should be taken into account. Firstly, the study was carried out in a single educational center in the province of Granada (Spain) with students aged 5-6 years, which makes it difficult to extrapolate these results to other contexts. For this reason, it would be interesting to perform the study in other contexts and extend the program to diverse age groups.

Another limitation of the research is to have a single source of evaluation, the person in charge of completing the questionnaires. In order to ensure objectivity, an evaluator hired for this research 
completed the questionnaires. It would be interesting to contrast this information with that obtained by other people close to the child, such as parents or teachers, favoring hetero evaluation.

Finally, it would also be interesting to analyze the impact of the program in the long term and to include other variables that may mediate with social and cognitive development, such as parents' educational styles.

Despite those limitations, one of the strengths of the EFE-P program is its usefulness for teachers, not only because its demonstrated effectiveness for improving executive functions and social competence in preschool settings, but also due to its contribution to promote sustainable development among kids. Executive functions appear central to policy formulation and the actual solutions of environmental problems. These high mental processes enable people to handle with new challenges and to adjust their behavior to contextual changes, to focus on a particular task, and to understand and consider when a complex event may require different perspectives, actions, or rules; and also allow them to stop thoughts or impulses that are not appropriate or efficient in a given situation. These skills play a key role in the way we interact with family and peers, at school or at work. What is more, improving executive functioning are stated the foundation of the imagination and the creation of a desired future [77]. At the same time that the EFE-P program includes methodologies required for sustainable development, its basic principle is learning through play, which facilitates children's involvement and interaction with the world around them.

In addition, as a program with independent units and depending on their availability, the teachers can adapt its implementation to the needs of their students and carry out training of a single or several executive components. Unlike many executive training programs, the EFE-P uses low-cost materials: no computers or other technological equipment is required to ensure that the intervention is also appropriate for low-income schools, where children are more likely to have executive deficits. In this way, the gap in the level of executive functioning in at-risk students could be reduced. In conclusion, the design of executive training programs should be considered a priority for preventive and applied research in the psychosocial developmental fields.

Author Contributions: All authors have contributed equally. All authors have read and agreed to the published version of the manuscript.

Funding: This research received no external funding.

Conflicts of Interest: The authors declare no conflict of interest.

\section{References}

1. Porges, S.W.; Furman, S.A. The early development of the autonomic nervous system provides a neural platform for social behaviour: A polyvagal perspective. Infant Child Dev. 2011, 20, 106-118. [CrossRef]

2. Santos, A.J.; Daniel, J.R.; Antunes, M.; Coppola, G.; Trudel, M.; Vaughn, B.E. Changes in preschool children's social engagement positively predict changes in social competence: A three-year longitudinal study of Portuguese children. Soc. Dev. 2019, 29, 544-563. [CrossRef]

3. Sastre-Riba, S.; Fonseca-Pedrero, E.; Poch-Olivé, M. Early development of executive functions: A differential study. Ann. Psychol. 2015, 31, 552-561.

4. van Lier, P.A.; Deater-Deckard, K. Children's elementary school social experience and executive functions development: Introduction to a special section. J. Abnorm. Child Psychol. 2016, 44, 1-6. [CrossRef] [PubMed]

5. Durkin, K. Attachment to others. In Developmental Social Psychology. From Infancy to Old Age; Blackwell: Oxford, UK, 1995.

6. Proshasky, H.M.; Fabian, A.K.; Kaminoff, R. Place-identity: Physical world socialization of the self. J. Environ. Psychol. 1983, 3, 57-83. [CrossRef]

7. Ramkissoon, H.; Smith, L.D.G.; Weiler, B. Testing the dimensionality of place attachment and its relationships with place satisfaction and pro-environmental behaviours: A structural equation modelling approach. Tour. Manag. 2013, 36, 552-566. [CrossRef]

8. Ramkissoon, H.; Mavondo, F.; Uysal, M. Social involvement and park citizenship as moderators for quality-of-life in a national park. J. Sustain. Tour. 2018, 26, 341-361. [CrossRef] 
9. Aznar-Díaz, I.; Trujillo-Torres, J.M.; Romero-Rodríguez, J.M.; Campos-Soto, M.N. Kids YouTubers generation: Analysis of YouTube channels of the new child phenomena. Pixel-Bit 2019, 56, 113-128. [CrossRef]

10. Hinojo-Lucena, F.-J.; Aznar-Díaz, I.; Cáceres-Reche, M.-P.; Romero-Rodríguez, J.-M. Use of social networks for international collaboration among medical students. Educ. Médica 2018, 21, 137-141. [CrossRef]

11. Vandenbroucke, L.; Spilt, J.; Verschueren, K.; Piccinin, C.; Baeyens, D. The classroom as a developmental context for cognitive development: A meta-analysis on the importance of teacher-student interactions for children's executive functions. Rev. Educ. Res. 2018, 88, 125-164. [CrossRef]

12. Rubin, K.H.; Rose-Krasnor, L. Interpersonal problem solving and social competence in children. In Handbook of Social Development. A Lifespan Perspective; Van Hasselt, V.B., Hersen, M., Eds.; Springer: Boston, MA, USA, 1992; pp. 283-323.

13. Gresham, F.M. Conceptual and definitional issues in the assessment of children's social skills: Implications for classifications and training. J. Clin. Child Psychol. 1986, 15, 3-15. [CrossRef]

14. Hosokawa, R.; Katsura, T.A. Longitudinal study of socioeconomic status, family processes, and child adjustment from preschool until early elementary school: The role of social competence. Child Adolesc. Psychiatry Ment. Health 2017, 11, 1-28. [CrossRef] [PubMed]

15. Benítez, J.L.; Pichardo, M.C.; Berbén, T.G.; Cabezas, M.F.; Justicia, F.J.; Haro, E.F.D. Análisis de la estructura factorial de las puntuaciones de la "Preschool and Kindergarten Behavior Scale" en población española. Psicothema 2011, 23, 314-321.

16. Merrell, K.W. Preschool and Kindergarten Behaviour Rating Scales (PKBS-2); Pro-Ed: Austin, TX, USA, 2002.

17. Caporaso, J.S.; Boseovski, J.J.; Marcovitch, S. The individual contributions of three executive function components to preschool social competence. Infant. Child Dev. 2019, 28, 1-17. [CrossRef]

18. Vahedi, S.; Farrokhi, F.; Farajian, F. Social competence and behavior problems in preschool children. Iran. J. Psychiatry 2012, 7, 126-134. [PubMed]

19. Etel, E.; Yagmurlu, B. Social competence, theory of mind, and executive function in institution-reared turkish children. Int. J. Behav. Dev. 2015, 39, 519-529. [CrossRef]

20. Santa-Cruz, C.; Rosas, R. Mapping of executive functions. Estud. Psicol. 2017, 38, 284-310. [CrossRef]

21. Diamond, A. Executive functions. Annu. Rev. Psychol. 2013, 64, 135-168. [CrossRef]

22. Bardikoff, N.; Sabbagh, M. The differentiation of executive functioning across development: Insights from Developmental Cognitive Neuroscience. In New Perspectives on Human Development; Budwig, N., Turiel, E., Zelazo, P.D., Eds.; Cambridge University Press: Cambridge, UK, 2017; pp. 47-66.

23. Baptista, J.; Osório, A.; Martins, E.C.; Verissimo, M.; Martins, C. Does social-behavioral adjustment mediate the relation between executive function and academic readiness? J. Appl. Dev. Psychol. 2016, 46, 22-30. [CrossRef]

24. Denham, S.A.; Bassett, H.H.; Way, E.; Mincic, M.; Zinsser, K.; Graling, K. Preschoolers' emotion knowledge: Self-regulatory foundations, and predictions of early school success. Cogn. Emot. 2012, 26, 667-679. [CrossRef]

25. Rhoades, B.L.; Greenberg, M.T.; Domitrovich, C.E. The contribution of inhibitory control to preschoolers' social-emotional competence. J. Appl. Dev. Psychol. 2009, 30, 310-320. [CrossRef]

26. Gligorović, M.; Đurović, N.B. Inhibitory control and adaptive behaviour in children with mild intellectual disability. J. Intell. Disabil. Res. 2014, 58, 233-242. [CrossRef]

27. Kim, S.; Nordling, J.K.; Yoon, J.E.; Boldt, L.J.; Kochanska, G. Effortful control in "hot" and "cool" tasks differentially predicts children's behavior problems and academic performance. J. Abnorm. Child Psychol. 2013, 41, 43-56. [CrossRef] [PubMed]

28. Diamond, A.; Ling, D.S. Conclusions about interventions, programs, and approaches for improving executive functions that appear justified and those that, despite much hype, do not. Dev. Cogn. Neurosci. 2016, 18, 34-48. [CrossRef] [PubMed]

29. Carriedo, N.; Corral, A.; Montoro, P.R.; Herrero, L.; Rucián, M. Development of the updating executive function: From 7-year-olds to young adults. Dev. Psychol. 2016, 52, 666. [CrossRef] [PubMed]

30. McQuade, J.D.; Murray-Close, D.; Shoulberg, E.K.; Hoza, B. Working memory and social functioning in children. J. Exp. Child Psychol. 2013, 115, 422-435. [CrossRef]

31. Maddio, S.; Greco, C. Flexibilidad cognitiva para resolver problemas entre pares. ¿Difiere esta capacidad en escolares de contextos urbanos y urbanomarginales? Interam. J. Psychol. 2010, 44, 1-12. 
32. Huizinga, M.; Dolan, C.V.; van der Molen, M.W. Age-related change in executive function: Developmental trends and a latent variable analysis. Neuropsychologia 2006, 44, 2017-2036. [CrossRef] [PubMed]

33. Gogtay, N.; Giedd, J.N.; Lusk, L.; Hayashi, K.M.; Greenstein, D.; Vaituzis, A.C.; Nugent, T.F.; Herman, D.H.; Clasen, L.S.; Toga, A.W. Dynamic mapping of human cortical development during childhood through early adulthood. Proc. Natl. Acad. Sci. USA 2004, 101, 8174-8179. [CrossRef] [PubMed]

34. Garon, N.; Bryson, S.E.; Smith, I.M. Executive function in preschoolers: A review using an integrative framework. Psychol. Bull. 2008, 134, 31-60. [CrossRef] [PubMed]

35. Diamond, A. Normal development of prefrontal cortex from birth to young adulthood: Cognitive functions, anatomy, and biochemistry. In Principles of Frontal Lobe Function; Stuss, D.T., Knight, R.T., Eds.; Oxford University Press: Oxford, UK, 2002; pp. 466-503.

36. Wass, S.; Porayska-Pomsta, K.; Johnson, M.H. Training attentional control in infancy. Curr. Biol. 2011, 21, 1543-1547. [CrossRef]

37. Flook, L.; Smalley, S.L.; Kitil, M.J.; Galla, B.M.; Kaiser-Greenland, S.; Locke, J.; Ishijima, E.; Kasari, C. Effects of mindful awareness practices on executive functions in elementary school children. J. Appl. Sch. Psychol. 2010, 26, 70-95. [CrossRef]

38. Kray, J.; Ferdinand, N.K. How to improve cognitive control in development during childhood: Potentials and Limits of cognitive interventions. Child Dev. Perspect. 2013, 7, 121-125. [CrossRef]

39. Amani, M.; Koruzhdeh, E.; Taiyari, S. The effect of strengthening executive functions through group games on the social skills of preschool children. Games Health J. 2019, 8, 213-219. [CrossRef] [PubMed]

40. Webster-Stratton, C.; Reid, M.J.; Hammond, M. Treating children with early-onset conduct problems: Intervention outcomes for parent, child, and teacher training. J. Clin. Child Adolesc. Psychol. 2004, 33, 105-124. [CrossRef] [PubMed]

41. Greenberg, M.T.; Kusche, C.A.; Cook, E.T.; Quamma, J.P. Promoting emotional competence in school-aged children: The effects of the PATHS Curriculum. Dev. Psychopathol. 1995, 7, 117-136. [CrossRef]

42. Chuang, C.; Reinke, W.M.; Herman, K.C. Effects of a Universal Classroom Management Teacher Training Program on elementary children with aggressive behaviors. Sch. Psychol. 2020, 35, 128-136. [CrossRef]

43. Seyhan, G.B.; Karabay, S.O.; Tuncdemir, T.B.A.; Greenberg, M.T.; Domitrovich, C. The effects of promoting alternative thinking strategies preschool program on teacher-children relationships and children's social competence in turkey. Int. J. Psychol. 2019, 54, 61-69. [CrossRef]

44. Bodrova, E.; Leong, D.J. Tools of the Mind: A Vygotskian Early Childhood Curriculum. In International Handbook of Early Childhood Education; Fleer, M., van Oers, B., Eds.; Springer: Dordrecht, The Netherlands, 2018; pp. 1095-1111.

45. Raver, C.C.; Jones, S.M.; Li-Grining, C.; Zhai, F.; Bub, K.; Pressler, E. CSRP's impact on low-income preschoolers' preacademic skills: Self-regulation as a mediating mechanism. Child Dev. 2011, 82, 362-378. [CrossRef]

46. Diamond, A.; Lee, C.; Senften, P.; Lam, A.; Abbott, D. Randomized control trial of Tools of the Mind: Marked benefits to kindergarten children and their teachers. PLoS ONE 2019, 14, e0222447. [CrossRef] [PubMed]

47. Watts, T.W.; Gandhi, J.; Ibrahim, D.A.; Masucci, M.D.; Raver, C.C. The Chicago School Readiness Project: Examining the long-term impacts of an early childhood intervention. PLoS ONE 2018, 13, e0200144. [CrossRef] [PubMed]

48. Röthlisberger, M.; Neuenschwander, R.; Cimeli, P.; Michel, E.; Roebers, C.M. Improving executive functions in 5-and 6-year-olds: Evaluation of a small group intervention in prekindergarten and kindergarten children. Infant. Child Dev. 2012, 21, 411-429. [CrossRef]

49. Traverso, L.; Viterbori, P.; Usai, M.C. Improving executive function in childhood: Evaluation of a training intervention for 5-year-old children. Front. Psychol. 2015, 6, 525. [CrossRef] [PubMed]

50. Bergman Nutley, S.; Söderqvist, S.; Bryde, S.; Thorell, L.B.; Humphreys, K.; Klingberg, T. Gains in fluid intelligence after training non-verbal reasoning in 4-year-old children: A controlled, randomized study. Dev. Sci. 2011, 14, 591-601. [CrossRef]

51. Thorell, L.B.; Lindqvist, S.; Nutley, S.B.; Bohlin, G.; Klingberg, T. Training and transfer effects of executive functions in preschool children. Dev. Sci. 2009, 12, 106-113. [CrossRef]

52. Kloo, D.; Perner, J. Training transfer between card sorting and false belief understanding: Helping children apply conflicting descriptions. Child Dev. 2003, 74, 1823-1839. [CrossRef] [PubMed] 
53. Rueda, M.R.; Checa, P.; Combita, L.M. Enhanced efficiency of the executive attention network after training in preschool children: Immediate changes and effects after two months. Dev. Cogn. Neurosci. 2012, 2, 192-204. [CrossRef]

54. Rueda, M.R.; Rothbart, M.K.; McCandliss, B.D.; Saccomanno, L.; Posner, M.I. Training, maturation, and genetic influences on the development of executive attention. Proc. Natl. Acad. Sci. USA 2005, 102, 14931-14936. [CrossRef]

55. Kassai, R.; Futo, J.; Demetrovics, Z.; Takacs, Z.K. A meta-analysis of the experimental evidence on the near-and far-transfer effects among children's executive function skills. Psychol. Bull. 2019, 145, 165-188. [CrossRef]

56. Clerc, J.; Miller, P.H.; Cosnefroy, L. Young children's transfer of strategies: Utilization deficiencies, executive function, and metacognition. Dev. Rev. 2014, 34, 378-393. [CrossRef]

57. Reijnders, J.; van Heugten, C.; van Boxtel, M. Cognitive interventions in healthy older adults and people with mild cognitive impairment: A systematic review. Ageing Res. Rev. 2013, 12, 263-275. [CrossRef] [PubMed]

58. Thompson, T.W.; Waskom, M.L.; Garel, K.L.A.; Cardenas-Iniguez, C.; Reynolds, G.O.; Winter, R.; Gabrieli, J.D. Failure of working memory training to enhance cognition or intelligence. PLoS ONE 2013, 8, e63614. [CrossRef] [PubMed]

59. Melby-Lervåg, M.; Redick, T.S.; Hulme, C. Working memory training does not improve performance on measures of intelligence or other measures of "far transfer" evidence from a meta-analytic review. Perspect. Psychol. Sci. 2016, 11, 512-534. [CrossRef]

60. Sala, G.; Gobet, F. Working memory training in typically developing children: A meta-analysis of the available evidence. Dev. Psychol. 2017, 53, 671. [CrossRef] [PubMed]

61. Blair, C.; Razza, R.P. Relating effortful control, executive function, and false belief understanding to emerging math and literacy ability in kindergarten. Child Dev. 2007, 78, 647-663. [CrossRef] [PubMed]

62. Durlak, J.A.; Weissberg, R.P.; Dymnicki, A.B.; Taylor, R.D.; Schellinger, K.B. The impact of enhancing students' social and emotional learning: A meta-analysis of school-based universal interventions. Child Dev. 2011, 82, 405-432. [CrossRef]

63. Cebrián, G.; Palau, R.; Mogas, J. The Smart Classroom as a means to the development of ESD methodologies. Sustainability 2020, 12, 3010. [CrossRef]

64. Scionti, N.; Cavallero, M.; Zogmaister, C.; Marzocchi, G.M. Is cognitive training effective for improving executive functions in preschoolers? A systematic review and meta-analysis. Front. Psychol. 2019, 10, 2812. [CrossRef]

65. Bausela-Herreras, E.; Luque-Cuenca, T. Evaluación conductual de la función ejecutiva-Versión infantil (BRIEF-P, Versión Española): Fiabilidad y validez. Acta. Investig. Psicológica 2017, 7, 2811-2822. [CrossRef]

66. Gioia, G.A.; Espy, K.A.; Isquith, P.K. Behavior Rating Inventory of Executive Function, Preschool Version (BRIEF-P); Psychological Assessment Resources: Odessa, FL, USA, 2002.

67. Reynolds, C.R.; Kamphaus, R.W. Behavior Assessment System for Children. Parent Rating Scales; American Guidance Service; BASC: Rosette, UK, 1992.

68. González, J.; Fernández, S.; Pérez, E.; Santamaría, P. Sistema de Evaluación de la Conducta en niños y Adolescentes; BASC (Adaptación Española); TEA: Madrid, Spain, 2004.

69. Feng, Z.; Diehr, P.; Peterson, A.; McLerran, D. Selected statistical issues in group randomized trials. Annu. Rev. Public Health 2001, 22, 167-187. [CrossRef] [PubMed]

70. Wang, M. Generalized estimating equations in longitudinal data analysis: A review and recent developments. Adv. Stat. 2014, 2014, 1-11. [CrossRef] [PubMed]

71. McMillan, J.H.; Foley, J. Reporting and discussing effect size: Still the road less traveled. Pract. Assess. Res. Eval. 2011, 16, 1-12.

72. Cohen, J. Statistical Power Analysis for the Behavioral Sciences, 2nd ed.; New York University: New York, NY, USA, 1988.

73. Villardón-Gallego, L.; García-Carrión, R.; Yáñez-Marquina, L.; Estévez, A. Impact of the interactive learning environments in children's prosocial behavior. Sustainability 2018, 10, 2138. [CrossRef]

74. Schonert-Reichl, K.A.; Smith, V.; Zaidman-Zait, A.; Hertzman, C. Promoting children's prosocial behaviors in school: Impact of the "Roots of Empathy" Program on the social and emotional competence of school-aged children. Sch. Ment. Health 2012, 4, 1-21. [CrossRef] 
75. Blair, C.; Raver, C.C. Closing the achievement gap through modification of neurocognitive and neuroendocrine function: Results from a cluster randomized controlled trial of an innovative approach to the education of children in kindergarten. PLoS ONE 2014, 9, e112393. [CrossRef] [PubMed]

76. Dias, N.M.; Seabra, A.G. Intervention for executive functions development in early elementary school children: Effects on learning and behaviour, and follow-up maintenance. Educ. Psychol. 2017, 37, 468-486. [CrossRef]

77. Ernst, J.; Burcak, F. Young children's contributions to sustainability: The influence of nature play on curiosity, executive function skills, creative thinking, and resilience. Sustainability 2019, 11, 4212. [CrossRef]

(C) 2020 by the authors. Licensee MDPI, Basel, Switzerland. This article is an open access article distributed under the terms and conditions of the Creative Commons Attribution (CC BY) license (http://creativecommons.org/licenses/by/4.0/). 